\title{
Severe reaction following a combined vaccine
}

\author{
S T Kudagammana ${ }^{1}$, C K Abeysekera ${ }^{2}$ \\ Sri Lanka Journal of Child Health, 2005; 34: 96-7
}

(Key words: adverse reaction, $\mathrm{DPT}+\mathrm{HepB}+\mathrm{Hib}$ vaccine)

\section{Introduction}

With the expanded programme of immunization (EPI) achieving near $100 \%$ coverage, the demand for non-EPI vaccines is rising. The combined vaccines have become popular among health care providers and the patients due to easier administration and a single injection covering many diseases. They have been shown to be safe and effective $e^{1,2}$. We report a child who developed a severe febrile illness following a combined DPT + HepB + Hib vaccine.

\section{Case report}

A one and a half year old girl who has been previously well was given OPV + combined $\mathrm{DPT}+\mathrm{HepB}+\mathrm{Hib}$ vaccine. She developed high fever within 8 hours.

During the next 2 days child continued to have fever spikes ranging from $38-39^{\circ} \mathrm{C}$ but her general condition remained well. On the third day she developed an urticarial rash with angioedema and was treated with antihistamines and 2 doses of hydrocortisone. Following day child was found to have moderate jaundice. She continued to have wildly swinging temperatures which were difficult to control with paracetamol. Examination revealed bilateral ankle swelling and tender hepatomegaly.

Following results were obtained from investigations done during this stage. Bile was present in the urine. The total white cell count was $20 \times 10^{9} / 1$ with a differential count of $79 \%$ neutrophils and $19 \%$ lymphocytes. Platelet count was $523 \times 10^{9} / 1$ and the haemoglobin was $9.6 \mathrm{~g} / \mathrm{dl}$. Blood film was negative for malarial parasites. Serum bilirubin was $71 \mu \mathrm{mol} / 1$. SGPT was $476 \mathrm{u} / 1$ and SGOT $126 \mathrm{u} / 1$. In the peripheral blood film red cells were hypochromic and microcytic; white cells were predominantly neutrophil with no abnormal cells; platelets were

${ }^{1}$ Senior Registrar in Paediatrics, Teaching Hospital, Peradeniya, ${ }^{2}$ Senior Lecturer and Head of Department, Faculty of Medicine, Peradeniya.

(Received on 9 December 2004)

normal in appearance. Blood urea was $2.3 \mathrm{mmol} / 1$, serum sodium $139 \mathrm{mmol} / 1$ and serum potassium 4.2 $\mathrm{mmol} / 1$. Prothrombin time was 14 seconds (control 12 seconds). Ultrasound scan of the abdomen was unremarkable except for a non-specific mild hepatomegaly.

Child was started on intravenous cefotaxime and gentamicin after a lumbar puncture was done and samples of urine and blood obtained for culture. Cerebrospinal fluid did not show any abnormality. Urine and blood cultures were negative. Despite antibiotic therapy child remained febrile, irritable and ill and complained of painful limbs. The results of investigations at this stage were as follows:

Total white cell count was $30 \times 10^{9} / 1$ with a differential count of $70 \%$ neutrophils and 29\% lymphocytes. ESR was $132 \mathrm{~mm}$ in first hour. The chest $\mathrm{x}$-ray, electrocardiogram and echocardiogram were normal. Cold agglutinins, mycoplasma antibodies, antinuclear antibodies and rheumatoid factor were negative. There was no growth in blood and urine cultures. Hepatitis B surface antigen and Hepatitis A IgM were negative.

Although the results of investigations were inconclusive, antibiotics were continued for a period of 7 days. She made a slow recovery and became asymptomatic by the 12th day. The full blood count, ESR and liver function tests were repeated after 4 weeks and were normal.

\section{Discussion}

Mild febrile reactions that settle in 2-3 days and local reactions at the site of injection site following immunizations are common. Very rarely anaphylaxis, allergic reactions and serum sickness like diseases have been reported ${ }^{1}$. Thrombocytopenia ${ }^{3}$, GuillainBarre syndrome, Bell palsy, abnormal liver function tests and convulsions have been reported with Hepatitis B containing vaccines ${ }^{4,5,6}$. Severe prolonged febrile illness with hepatitis following the combined $\mathrm{DPT}+\mathrm{HepB}+\mathrm{Hib}$ has not been documented. Clinicians have to be aware of the possibility of this type of reaction following combined vaccines. 


\section{References}

1. Pfeiderer M. Perspective and view on proving safety and immunogenicity of combined vaccines. Proceedings of 19th VHPB meeting of European Regulatory Authorities on combined Hepatitis B vaccine. 2001 Oct 22-23; Malta.

2. Hepatitis B fact sheet. National Centre for infectious Diseases, US Department of Health and Human Services, http://www.cdc.gov/ncidod diseases/hepatitis/b/factvax.htm. Accessed Nov 20, 2004.

3. Muller A, Kertzscher F, Kiefel V. Thrombocytopenic purpura; adverse reaction to a combined immunization (recombinant hepatitis 5 and measles-mumps-rubella-vaccine) and after therapy with co-trimoxazole. European Journal of Paediatrics 1999; 158:15.
4. Tongol M A S. editor, MIMS Annual Sri Lanka 6th ed. Singapore; MediMedia Asia Pte Ltd. 2004:682-3.

5. Jayasuriya L, Weerasinghe A. editors, Guidelines for the use of non-EPI vaccines. Colombo; Sri Lanka Medical Association 2001:10-3.

6. Frequently asked questions about vaccines. National vaccine information centre, VaccineAwareness of North Florida Inc. http://www.know-vaccines.org/faq.html. Accessed Nov 20, 2004. 
